\title{
DEVELOPMENT OF A NEW ENERGY-EFFICIENT HYBRID SOLAR-ASSISTED AIR CONDITIONING SYSTEM
}

*V. Vakiloroaya, R. Ismail, and Q.P. Ha

School of Electrical, Mechanical and Mechatronic Systems, University of Technology, Sydney, Australia (*Corresponding author: vahid.vakiloroaya@engineer.com) 


\begin{abstract}
The paper aims at developing a hybrid solar-assisted air conditioner system for performance enhancement and energy efficiency improvement. To increase sub-cooling of the refrigerant at partial loads, we propose a new discharge bypass line together with an inline solenoid valve, installed after the compressor to regulate the mass flow rate of the refrigerant vapour passing through a hot water storage tank. For control design, a lumped parameter model is first developed to describe the dynamics of the system in an explicit form of input-output relationship. The system has been fully-instrumented to examine its performance under different operation conditions. The system model is then validated by extensive experimental tests. The predictions from the models exhibit a good coincidence with experimental results, judging by an RMS error less than $15 \%$. Based on the obtained dynamic model, a linear quadratic regulator (LQR) is applied to optimize a cost function of the output errors and control efforts. The key challenge is to regulate the refrigerant temperature entering the condenser by controlling the valve opening. The design approach is then tested in a transient simulation tool to predict the system performance in transient conditions. The experimental results obtained from implementation with PLC demonstrate that the proposed system delivers higher system efficiency owing to the higher refrigeration effect in the direct expansion evaporator. Thus, the novel development is promising for improvement of energy efficiency, enhancement of the system performance while fulfilling the cooling demand. Consequently, between 25 and $43 \%$ of monthly electricity can be saved on average.
\end{abstract}

\title{
KEYWORDS
}

Energy Saving, Linear Quadratic Regulator, Solar-Assisted Air-Conditioner, Sub-cooling

\section{INTRODUCTION}

Heating, ventilation and air conditioning (HVAC) systems are responsible for about $55 \%$ of the total energy consumption in buildings [Al-Abidi et al., 2012]. They also lead to the reduction of the valuable fossil fuel sources and production of the greenhouse gases which are known to cause ozone layer depletion [Choudhury et al., 2010]. Therefore, in recent years due to world energy shortage, different types of cooling technologies in combination with solar thermal energy have been explored. Technically, solar energy is applied to air conditioning systems either by photovoltaic panels or heat driven sorption systems. Applying solar energy on various types of HVAC systems has proved its enormous potential for energy usage reduction. However, solar radiation is a highly time-dependent energy source and it is not necessarily match with building demand. This problem can be addressed by storing and releasing thermal energy according to the building load. Therefore, an appropriate control method should be employed by solar-assisted HVAC systems to adjust the transient building demand with the stored solar thermal energy.

Among different type of HVAC systems, the direct expansion (DX) wall-mounted air-conditioner with a vapor compression cycle is commonly-used. This system that uses energy obtained by fossil fuels can output two to six times thermal energy through absorption from renewable energy sources [Fu et al., 2012]. However, air-cooled air conditioning systems are less energy efficient than water-cooled air conditioning system [Liang et al., 2011] and thus finding novel ways to reduce its energy consumption in buildings without compromising comfort and indoor air quality is an ongoing research challenge. A large number of theoretical and experimental investigations on solar-assisted HVAC systems have been reported. A solar powered absorption refrigeration system with mass energy transformation and storage technology was presented by [Xu et al., 2011] to balance the inconsistency between the solar radiation and the cooling load. They obtained a system COP of 0.7525 for the air-cooled condenser and 0.7555 for the water-cooled condenser. The performance of a condenser heat recovery with a PV/T air heating collector to regenerate desiccant for reducing energy use of an air conditioning room was investigated by [Sukamongkol et al., 2010]. Their experimental test and dynamic simulation indicated that electricity of about $6 \%$ of the daily total solar radiation can be gained from the PV/T collector. The proposed system was able to save about $18 \%$ of the total energy use of the air conditioner. [Guo and Shen, 2009] presented a dynamic model for investigating the performance of a solar-driven ejector refrigeration plant for an office building. Their 
results demonstrated that the proposed system could conserve more than $75 \%$ of electricity compared with a traditional compressor based air conditioner. [La et al., 2011] combined a solar driven two-stage rotary desiccant cooling plant with a vapour compression air conditioning system and experimentally investigated its performance. They found that the solar driven desiccant cooling system can handle about $33 \%$ of the cooling load which means $34 \%$ reduction in power consumption compared with conventional a vapor compression system. However, no research work has reported about the influence of solar vacuum collectors installed after the compressor on the energy performance of vapor compression air conditioning systems by using combined simulation of building dynamic behavior validated with operational data collected from a real-world tested system.

The objective of this study is to describe a newly-developed hybrid solar-assisted air conditioning system and report on its system performance optimized by using an efficient methodology for dynamic scheduling and optimal control of the system that can be implemented on-line. A control scheme is developed using the linear quadratic regulator (LQR) technique. In the solar-assisted unit under investigation, the solar collector is installed after the compressor in order to reduce the compressor work to produce the required essential temperature for the refrigerant entering the condenser. Therefore, the compressor can be sized solely with additional heat input for the condenser heat rejection by the solar collector, which allows the system to save around $40 \%$ of electrical energy. However, it increases the refrigerant temperature leaving the condenser because of the additional heat added before the condenser especially in partial load conditions. This results in some reduction of the system coefficient of performance (COP). Therefore, the optimum set-points for the refrigerant temperature entering the condenser should lower the refrigerant temperature leaving the condenser and, in turn, increase system overall COP. In principle, a proper control strategy for the refrigerant temperature entering the condenser can lead to more energy-efficient operations [Vakiloroaya et al., 2013]. To achieve this, an appropriate modification should be applied to adapt the plant with changing operational conditions caused by a transient cooling load and varying ambient conditions. Here, a novel configuration including a by-pass line together with a three-way proportional valve is proposed in the discharge line after the compressor in order to control the refrigerant temperature [Ha and Vakiloroaya, 2012]. The control objective is to regulate the refrigerant flow rate in order to enhance the sub-cool temperature for various cooling loads and ambient conditions. Mathematical models and experimental data are implemented on a transient simulation tool, TRNSYS 16 [TRNSYS Software 2006], to predict performance of the system. Results show that the new implemented mechanical design together with its proposed control system can yield to higher sub-cool temperature after the condenser which can increase further the overall coefficient of performance up to $9 \%$.

\section{SYSTEM DESCRIPTION}

A single stage vapour compression solar air-conditioner consists of six major components: a compressor, a condenser, an expansion device, an evaporator, a solar vacuum collector and a solar storage tank. The schematic diagram of the arrangement is shown in Fig. 1. The cycle starts with a mixture of liquid and vapour refrigerant entering the evaporator (point 1). The heat from the warm air is absorbed by an evaporator coil. During this process, the state of the refrigerant is changed from a liquid to a gas and becomes superheated at the evaporator exit. The superheat vapour enters the compressor (point 2), where the increasing pressure causes to raise the refrigerant temperature. A vacuum solar panel installed after the compressor uses the sun radiation to heat up the water. An insulated water storage tank is connected to the vacuum solar collector to maintain the water temperature. The refrigerant from the compressor goes through the copper coil inside the tank and undertakes a heat exchange (point 3). The vacuum solar collector reheats the refrigerant to reach the necessary superheat temperature in order to reduce the required electrical energy to run the compressor. The system is extensively equipped with sensors and data logging device as a demonstrator for green automation technologies for building HVAC [Ha, 2012].

However, the refrigerant temperature that results from the smaller compressor is 5 to 10 degrees less than what is required for the condenser heat rejection to be effective; this shortfall is made up by an 


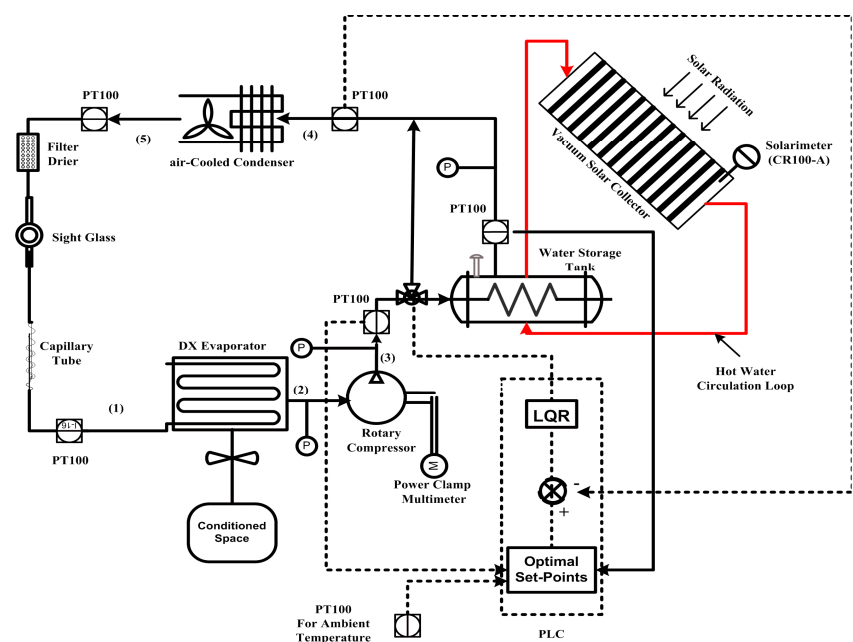

Figure 1 - Schematic diagram of a hybrid solar assisted air conditioner

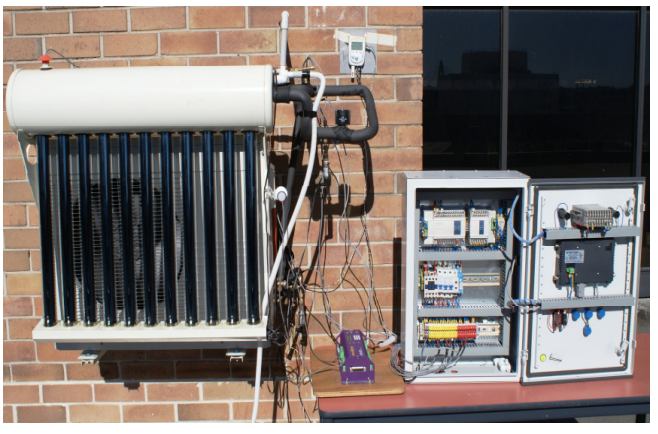

Figure 2 - Experimental hybrid solar-assisted air conditioner with its PLC implementation

additional heat input from solar collectors. At this point, the high pressure superheated gas travels to the condenser for heat rejection to the ambient air. A further reduction in temperature happens in the condenser and causes it to de-superheat; thus, the refrigerant liquid is sub-cooled as it enters the capillary tube. The high pressure sub-cooled refrigerant flows through the capillary tube, which reduces both its pressure and temperature. A disadvantage of this approach is that the storage tank tends to increase the refrigerant vapor temperature entering the condenser at any time, even under partial load conditions where there is no benefit. In fact, under certain conditions, this can even reduce performance, as the condensing temperature is not constant, but influenced by changes in the ambient air temperature. For optimum performance, the refrigerant temperature at the condenser inlet can be lower at partial loads than it needs to be at full load. For this reason, a new discharge bypass line together with its two-way on/off solenoid valve is installed after the compressor to regulate the refrigerant mass flow rate [Ha and Vakiloroaya, 2012]. Therefore, the solenoid valve can adjust the temperature of the refrigerant entering the condenser. During a high cooling demand when the condensing temperature is high, the solenoid valve is closed, directing the refrigerant vapor from the compressor into the copper coil inside the storage tank, where it acquires additional heat from the hot water. The decrease of the refrigerant temperature entering the condenser leads to a reduction in the refrigerant temperature leaving the condenser. This means a more substantial sub-cooling at the condenser outlet and therefore a reduction of the refrigerant temperature entering the evaporator. This enhances the system refrigeration effect and thereby its coefficient of performance. The following section describes the mathematical model for system components for the control purpose, by applying the energy and mass balance to obtain a lumped-parameter moving-boundary dynamics of the system.

\section{Modeling}

Based on the heat transfer processes in the system, ordinary differential or difference equations (ODEs) are developed. In many intricate cases, the problem may be too complicated to explicitly solve, recursive identification algorithms are used based on simplification of the energy balance equations. The proposed design for the system can be mainly characterized by the refrigerant temperatures leaving the compressor, leaving the condenser and leaving the storage tank with the control variable being the refrigerant mass flow rate, $u=\dot{m}_{r}$. In this section, mathematical models are derived describing the system dynamics for the control design purpose. The energy balance principle for the condenser coil gives:

$$
\frac{d T_{r l c}}{d t}=\frac{d T_{a m b}}{d t}\left(1-\exp \left(-\frac{A_{c o n} K_{c o n}}{\dot{m}_{r} C_{p, r}}\right)\right)+\frac{d T_{r e c}}{d t} \exp \left(-\frac{A_{c o n} K_{c o n}}{\dot{m}_{r} C_{p, r}}\right),
$$


where $T_{r l c}$ and $T_{r e c}$ are respectively the temperature of refrigerant leaving and entering the condenser, $T_{a m b}$ is the ambient temperature, $A_{c o n}$ and $K_{c o n}$ are respectively condenser coil area and heat transfer coefficient, and $\dot{m}_{r}$ and $C_{p, r}$ are respectively refrigerant mass flow rate and heat capacity. The energy balance for the newly-installed discharge bypass line yields:

$\dot{m}_{r} \frac{d T_{r e c}}{d t}=\dot{m}_{r e l} \frac{d T_{\text {comp }}}{d t}+\dot{m}_{r e s} \frac{d T_{w s t}}{d t}$

where $T_{\text {wst }}$ and $T_{\text {comp }}$ are respectively the refrigerant temperature leaving the water storage tank and compressor, and $\dot{m}_{r e l}$ and $\dot{m}_{r e s}$ are the mass flow rate of the refrigerant respectively entering the bypass line and storage tank. Substituting (2) into (1) gives:

$$
\frac{d T_{r l c}}{d t}=\frac{d T_{a m b}}{d t}\left(1-\exp \left(-\frac{A_{c o n} K_{c o n}}{\dot{m}_{r} C_{p, r}}\right)\right)+\left[\frac{\dot{m}_{r e l}}{\dot{m}_{r}} \frac{d T_{c o m p}}{d t}+\frac{\dot{m}_{r e s}}{\dot{m}_{r}} \frac{d T_{w s t}}{d t}\right] \exp \left(-\frac{A_{c o n} K_{c o n}}{\dot{m}_{r} C_{p, r}}\right) .
$$

The energy balance principle for the immersed coil inside the storage tank gives:

$$
\begin{aligned}
& \frac{d T_{w s t}}{d t}=\frac{d T_{\text {comp }}}{d t} \exp \left(-\frac{A_{\text {eva }} K_{\text {eva }}}{\dot{m}_{r} C_{p, r}}\right)+\left[\frac{A I \tau_{s} \alpha_{s}}{M_{w} C_{p, w}}+\frac{A_{t} K_{t}}{M_{w} C_{p, w}}\left(T_{a m b}-T_{w}\right)\right]\left(1-\exp \left(-\frac{A_{h x} K_{h x}}{\dot{m}_{r} C_{p, r}}\right)+\right. \\
& \frac{\dot{m}_{r} C_{p, r}}{M_{w} C_{p, w}}\left(1-\exp \left(-\frac{A_{h x} K_{h x}}{\dot{m}_{r} C_{p, r}}\right)\left(T_{\text {comp }}-T_{w s t}\right),\right.
\end{aligned}
$$

where $T_{w}$ is the temperature of the refrigerant leaving the storage tank and also of the water inside the storage tank, $A_{h x}$ and $K_{h x}$ are respectively the tank immersed coil area and heat transfer coefficient, $T_{a m b}$ is the ambient temperature, $M_{w}$ and $C_{p, r}$ are respectively the water mass and heat capacity, $A_{t}$ and $K_{t}$ are respectively storage tank area and heat transfer coefficient, $\alpha_{s}$ and $\tau_{s}$ are respectively vacuum collector absorptance and transmittance, $I$ is the total solar radiation intensity, and $A_{c o l}$ is the collector area. The energy balance principle for the compressor gives:

$$
\frac{d T_{\text {comp }}}{d t}=\frac{d T_{i n}}{d t}\left(1-\exp \left(-\frac{A_{\text {eva }} K_{\text {eva }}}{\dot{m}_{r} C_{p, r}}\right)\right)+\frac{d T_{r e c}}{d t} \exp \left(-\frac{A_{c o n} K_{c o n}}{\dot{m}_{r} C_{p, r}}\right)+b \dot{m}_{r},
$$

where

$b=\frac{\dot{m}_{r e l}}{\dot{m}_{r}}\left[1-\exp \left(-\frac{A_{c o n} K_{c o n}}{\dot{m}_{r} C_{p, r}}-\frac{A_{e v a} K_{e v a}}{\dot{m}_{r} C_{p, r}}\right)\right]+\frac{\dot{m}_{r e s}}{\dot{m}_{r}} \exp \left(-\frac{A_{c o n} K_{c o n}}{\dot{m}_{r} C_{p, r}}\right)$,

where $A_{\text {eva }}$ and $K_{\text {eva }}$ are respectively the evaporator coil area and heat transfer coefficient, and $T_{i n}$ is the room temperature. Substituting (2) into (5) gives:

$$
\frac{d T_{\text {comp }}}{d t}=\frac{d T_{\text {in }}}{d t}\left(1-\exp \left(-\frac{A_{\text {eva }} K_{\text {eva }}}{\dot{m}_{r} C_{p, r}}\right)\right)+\left(\frac{\dot{m}_{r e l}}{\dot{m}_{r}} \frac{d T_{c o m p}}{d t}+\frac{\dot{m}_{r e s}}{\dot{m}_{r}} \frac{d T_{w s t}}{d t}\right) \exp \left(-\frac{A_{c o n} K_{c o n}}{\dot{m}_{r} C_{p, r}}\right)+b \dot{m}_{r} .
$$

Solving simultaneously equations (4) and (7) gives: 
$\frac{d T_{c o m p}}{d t}=\frac{\left(\frac{\dot{m}_{r e s}}{\dot{m}_{r}}\right)\left(a_{1}+a_{2}\left(T_{c o m p}-T_{w s t}\right)\right) \exp \left(-\frac{A_{c o n} K_{c o n}}{\dot{m}_{r} C_{p, r}}\right)+a_{3}+b \dot{m}_{r}}{\left[1-\exp \left(-\frac{A_{c o n} K_{c o n}}{\dot{m}_{r} C_{p, r}}\right)\right]}$

$\frac{d T_{w s t}}{d t}=\frac{\left(a_{1}+a_{2}\left(T_{c o m p}-T_{w s t}\right)\right)\left[1-\exp \left(-\frac{A_{c o n} K_{c o n}}{\dot{m}_{r} C_{p, r}}\right)-\frac{\dot{m}_{r e s}}{\dot{m}_{r}} \exp \left(-\frac{A_{\text {eva }} K_{\text {eva }}}{\dot{m}_{r} C_{p, r}}-\frac{A_{\text {con }} K_{c o n}}{\dot{m}_{r} C_{p, r}}\right)\right]}{1-\exp \left(-\frac{A_{c o n} K_{c o n}}{\dot{m}_{r} C_{p, r}}\right) .}+$

$$
\frac{\exp \left(-\frac{A_{\text {eva }} K_{\text {eva }}}{\dot{m}_{r} C_{p, r}}\right)\left(a_{3}+b \dot{m}_{r}\right)}{1-\exp \left(-\frac{A_{c o n} K_{c o n}}{\dot{m}_{r} C_{p, r}}\right)},
$$

where

$$
\begin{aligned}
& a_{1}=\left[\frac{A I \tau_{s} \alpha_{s}}{M_{w} C_{p, w}}+\frac{A_{t} K_{t}}{M_{w} C_{p, w}}\left(T_{a m b}-T_{w}\right)\right]\left(1-\exp \left(-\frac{A_{h x} K_{h x}}{\dot{m}_{r} C_{p, r}}\right),\right. \\
& a_{2}=\frac{\dot{m}_{r} C_{p, r}}{M_{w} C_{p, w}}\left(1-\exp \left(-\frac{A_{h x} K_{h x}}{\dot{m}_{r} C_{p, r}}\right),\right. \\
& a_{3}=\frac{d T_{\text {in }}}{d t}\left(1-\exp \left(-\frac{A_{\text {eva }} K_{\text {eva }}}{\dot{m}_{r} C_{p, r}}\right)\right) .
\end{aligned}
$$

Substituting (8) and (9) into (3) yields:

$$
\begin{aligned}
& \frac{d T_{r l c}}{d t}=a_{4}+\frac{\left(a_{1}+a_{2}\left(T_{c o m p}-T_{w s t}\right)\right)\left[\frac{\dot{m}_{r e l} \dot{m}_{r e s}}{\dot{m}_{r}^{2}} \exp \left(-\frac{A_{c o n} K_{c o n}}{\dot{m}_{r} C_{p, r}}\right)+\frac{\dot{m}_{r e s}}{\dot{m}_{r}}\left(1-\exp \left(-\frac{A_{c o n} K_{c o n}}{\dot{m}_{r} C_{p, r}}\right)\right)\right]}{\left[1-\exp \left(-\frac{A_{c o n} K_{c o n}}{\dot{m}_{r} C_{p, r}}\right)\right]}+ \\
& \frac{\dot{m}_{r e l}}{\dot{m}_{r}}\left(a_{3}+b \dot{m}_{r}\right)-\left(\frac{\dot{m}_{r e s}}{\dot{m}_{r}}\right)^{2} \exp \left(-\frac{A_{\text {eva }} K_{\text {eva }}}{\dot{m}_{r} C_{p, r}}-\frac{A_{c o n} K_{c o n}}{\dot{m}_{r} C_{p, r}}\right) \\
& {\left[1-\exp \left(-\frac{A_{c o n} K_{c o n}}{\dot{m}_{r} C_{p, r}}\right)\right]}
\end{aligned}
$$

where

$$
a_{4}=\frac{d T_{a m b}}{d t}\left(1-\exp \left(-\frac{A_{c o n} K_{c o n}}{\dot{m}_{r} C_{p, r}}\right)\right) .
$$


Here, by assuming isentropic operations of the compressor and assigning the system state variables as the temperatures of the refrigerant when leaving the condenser $\left(T_{r l c}\right)$, leaving the water storage tank $\left(T_{w s t}\right)$, and leaving the compressor $\left(T_{\text {comp }}\right)$, a linearized non-affine model of the designed hybrid system is obtained as:

$$
\dot{x}=A x+B u, y=C x,
$$

where $x=\left[\begin{array}{lll}T_{\text {rlc }} & T_{\text {wst }} & T_{\text {comp }}\end{array}\right]^{T}, u$ is the current applied to the in-line solenoid valve $(0 \mathrm{~mA} \leq u \leq 20 \mathrm{~mA})$, and the system output is the temperature of the refrigerant leaving the compressor $y=T_{\text {comp }}$. The system matrices are given by:

$$
A=\left[\begin{array}{lll}
0 & a_{12} & -a_{12} \\
0 & a_{22} & -a_{22} \\
0 & a_{32} & -a_{32}
\end{array}\right], \quad B=\left[\begin{array}{c}
0 \\
b_{21} \\
b_{31}
\end{array}\right], C=\left[\begin{array}{lll}
0 & 0 & 1
\end{array}\right],
$$

where

$a_{12}=-\frac{\frac{\dot{m}_{r e l} \dot{m}_{r e s}}{\dot{m}_{r}^{2}} \exp \left(-\frac{A_{c o n} K_{c o n}}{\dot{m}_{r} C_{p, r}}\right)+\frac{\dot{m}_{r e s}}{\dot{m}_{r}}\left(1-\exp \left(-\frac{A_{c o n} K_{c o n}}{\dot{m}_{r} C_{p, r}}\right)\right)}{1-\exp \left(-\frac{A_{c o n} U_{c o n}}{\dot{m}_{r} C_{p, r}}\right)} a_{2}$,

$a_{22}=-\frac{\left[1-\exp \left(-\frac{A_{c o n} K_{c o n}}{\dot{m}_{r} C_{p, r}}\right)-\frac{\dot{m}_{r e s}}{\dot{m}_{r}} \exp \left(-\frac{A_{\text {eva }} K_{\text {eva }}}{\dot{m}_{r} C_{p, r}}-\frac{A_{c o n} K_{c o n}}{\dot{m}_{r} C_{p, r}}\right)\right]}{1-\exp \left(-\frac{A_{c o n} U_{c o n}}{\dot{m}_{r} C_{p, r}}\right)} a_{2}$,

$a_{32}=-\frac{a_{2}\left(\frac{\dot{m}_{r e s}}{\dot{m}_{r}}\right) \exp \left(-\frac{A_{c o n} U_{c o n}}{\dot{m}_{r} C_{p, r}}\right)}{1-\exp \left(-\frac{A_{c o n} U_{c o n}}{\dot{m}_{r} C_{p, r}}\right)}$

$b_{21}=-\frac{k b \exp \left(-\frac{A_{\text {eva }} K_{\text {eva }}}{\dot{m}_{r} C_{p, r}}\right)}{1-\exp \left(-\frac{A_{c o n} U_{c o n}}{\dot{m}_{r} C_{p, r}}\right)}$,

$$
b_{31}=-\frac{k b}{1-\exp \left(-\frac{A_{c o n} U_{c o n}}{\dot{m}_{r} C_{p, r}}\right)},
$$


in which $k$ is the coefficient of the relationship between the mass flow rate of the refrigerant and the current applied to the control valve.

\section{Experimental Rig}

Experimental work was carried out using a newly-developed solar-assisted DX hybrid air conditioner, as shown in Fig. 2. The experimental set-up is mainly composed of two parts: an airconditioned room served by the direct expansion evaporator unit, and the condensing unit combined with a solar vacuum collector. The nominal output cooling capacity of the air-conditioner is $6 \mathrm{~kW}$. The plant has one scroll hermetic compressor using refrigerant R410A as a working fluid. The amount of charged refrigerant into the system is $1.8 \mathrm{~kg}$. The design air flow rate of the evaporator fan is $850 \mathrm{~m}^{3} / \mathrm{h}$. The condenser in the plant is an air-cooled tube and uses a coated fin tube. The design air flow rate of the condenser axial fan is $2500 \mathrm{~m}^{3} / \mathrm{h}$ and its rated power input is $50 \mathrm{~W}$. The collector is integrated at a tilted angle of $5^{\circ}$ and oriented towards North (for usage in the southern hemisphere). The solar collector is made of 11 evacuated tubes with length $55 \mathrm{~cm}$ and diameter $10 \mathrm{~cm}$. The solar collector is equipped with a 35litre horizontal cylindrical storage tank, insulated by polyurethane of $55 \mathrm{~mm}$ thickness. This system has been fully-instrumented to facilitate a number of tests under different operation conditions [Vakiloroaya et al., 2012]. Field tests were run continuously to monitor the system performance at various weather conditions for two weeks. Day-long tests were carried out for 24 hours and all measured data was monitored in 10 minute intervals. All measurements were then computerised so that all the measured data could be recorded for subsequent analysis.

\section{CONTROL DESIGN}

In this section, a strategy is developed to control, via the proportional valve in the discharge line, the system states comprising the temperatures of the refrigerant leaving the condenser, leaving the compressor and leaving the storage tank. A proper regulation of these state variables and their dynamic behavior can lead to more energy-efficient operations. For the controller design, the performance index is proposed:

$$
J=\int_{0}^{\infty}\left(x^{T} Q x+u^{T} R u\right) d t
$$

where $Q=Q^{T}>0$ and $R=R^{T}>0$ are respectively the state and control penalty matrices.

The purpose is to construct a stabilizing linear state-feedback controller of the form $u=-K x$ that minimizes the performance index $J$. Let denote such a linear control law by $u^{*}$. The LQR optimal control law is expressed as:

$$
u^{*}=-R^{-1} B^{T} P x=-K x
$$

where $K=R^{-1} B^{T} P$, in which matrix $P$ is obtained by solving the following algebraic Riccati equation:

$$
A^{T} P+P A+Q-P B R^{-1} B^{T} P=0 .
$$

By solving (27) for matrix $P$, we can obtain the control gain $K$ for the optimal control input. The set-point generation for the aforementioned variables has been determined by using the sequential quadratic programming as described in [Ha and Vakiloroaya, 2012]. Then the optimal references together with LQR control signal were implemented in the PLC to command the in-line valve to adjust the refrigerant mass flow rate and ultimately control the refrigerant temperatures. 


\section{RESULTS AND DISSCUSION}

The collected experimental data and the system components are configured and assembled using a fully integrated visual interface known as the TRNSYS simulation studio. By creating an input file, the proposed optimization algorithm was coded according to the mathematical method described in the previous section. The code is also included a subroutine to evaluate the thermodynamic properties of the refrigerant R410A. Furthermore, the building information file is created to meet the requirements of the ANSI/ASHRAE Standard 140-2007 [ANSI/ASHRAE Standard 140, 2007]. The heat transfer behavior of the system has been verified using the experimental data as obtained from testing [Vakiloroaya et al., 2012]. The implemented experimental data on the transient tool for ambient dry-bulb temperature and relative humidity are shown in Fig. 3. To represent comprehensively the system operations, the monitored data, embedded in the transient simulation program for the temperature profiles of the refrigerant leaving the capillary tube, direct expansion evaporator, rotary compressor and water temperature inside the storage tank are shown respectively in Fig. 4.

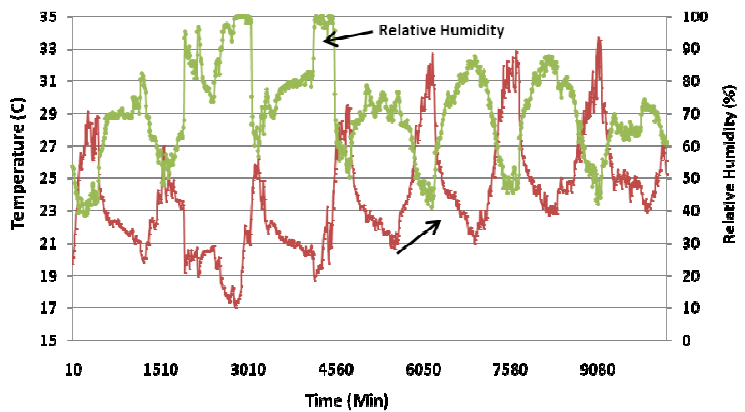

Figure 3 - Ambient conditions profile

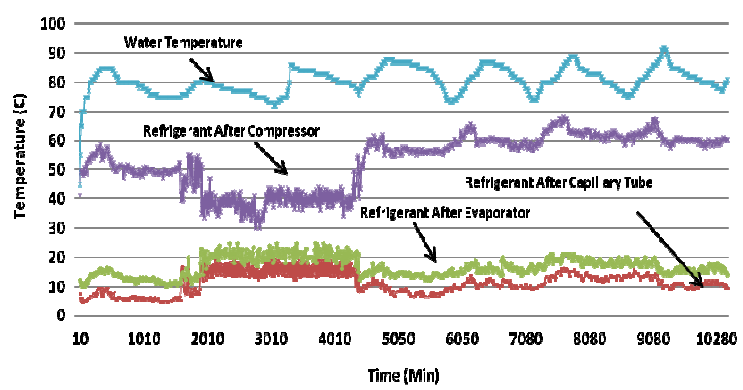

Figure 4 - Refrigerant temperature profile

\section{Performance Prediction}

The temperature variations of both the refrigerant entering and leaving the condenser with and without control are shown in Fig. 5. The results show that both temperatures will drop by using the new design. The reason is that in a conventional system, the temperature of the refrigerant leaving the condenser increases with any increase in the refrigerant temperature after the water storage tank while with the proposed design, this temperature is controlled according to the required refrigerant temperature entering the condenser. Furthermore, the lower refrigerant temperature leaving the condenser decreases the refrigerant temperature entering evaporator and in turn increases the refrigeration effects. On the other hand, as the refrigerant temperature in the condenser outlet drops, the refrigerant temperature in the evaporator inlet also drops and the enthalpy of the refrigerant entering the evaporator is lowered. This reduction allows enhancing the refrigeration effect significantly and thus increasing the evaporator capacity. Furthermore, sub-cooling the refrigerant after the condenser prevents flash gas forming at the inlet of the expansion device. Therefore as emphasized earlier, this approach can increase the system coefficient of performance. Simulation results indicated that the average COP by using the optimal set-point values is around 9\% more than under the commonly-used design. Moreover, the lower refrigerant enthalpy entering the evaporator tends to decrease the compressor work and in turn avoids the unnecessary heat rejection in the condenser. Furthermore, for both designs, the refrigerant vapor entering the suction inlet of the compressor is the same which means that the specific volume of the refrigerant vapor entering the compressor is same for conventional and newly-developed systems. Since the refrigerant flow rate in the proposed design is less than that in a conventional design, the compressor here could handle a smaller volume of the refrigerant vapour, which in turn reduces the compressor power consumption [Vakiloroaya et al., 2011]. Besides, a temperature reduction thanks to optimal control could yield to lessening the displacement volume of the compressor, and thereby reducing its work. In average, the compressor power consumption for the new design shows $6.25 \%$ energy savings compared to a conventional cycle. Furthermore, the enthalpy of the refrigerant entering the evaporator by using the proposed system is nearly 
$8.94 \%$ less than of a conventional system, which means more refrigeration effect for the evaporator can be expected from the developed system.

\section{Energy Analysis}

As discussed in the previous section, a higher refrigeration effect causes more heat transfer in the evaporator which increases the heat transfer efficiency of the DX evaporator. Therefore, less supply air will be required to provide the building cooling. Since the evaporator fan speed is constant, the colder air would support the space cooling and thus the building will achieve its desired temperature faster. As a result the compressor duty cycle is reduced to lessen its average electricity usage. Moreover, the lower refrigerant enthalpy entering the evaporator tends to decrease the compressor work and in turn avoids the unnecessary heat rejection in the condenser. The total energy usage of the whole system for each summer month, obtained by summation of system energy consumption in each working hour, is shown in Fig. 6 , wherein results of the simulated average energy consumption of a conventional system and the newlydeveloped air conditioning system can be compared for each summer month. It can be seen that the power consumption of new solar-assisted air conditioner is significantly less than the power usage of a conventional plant.

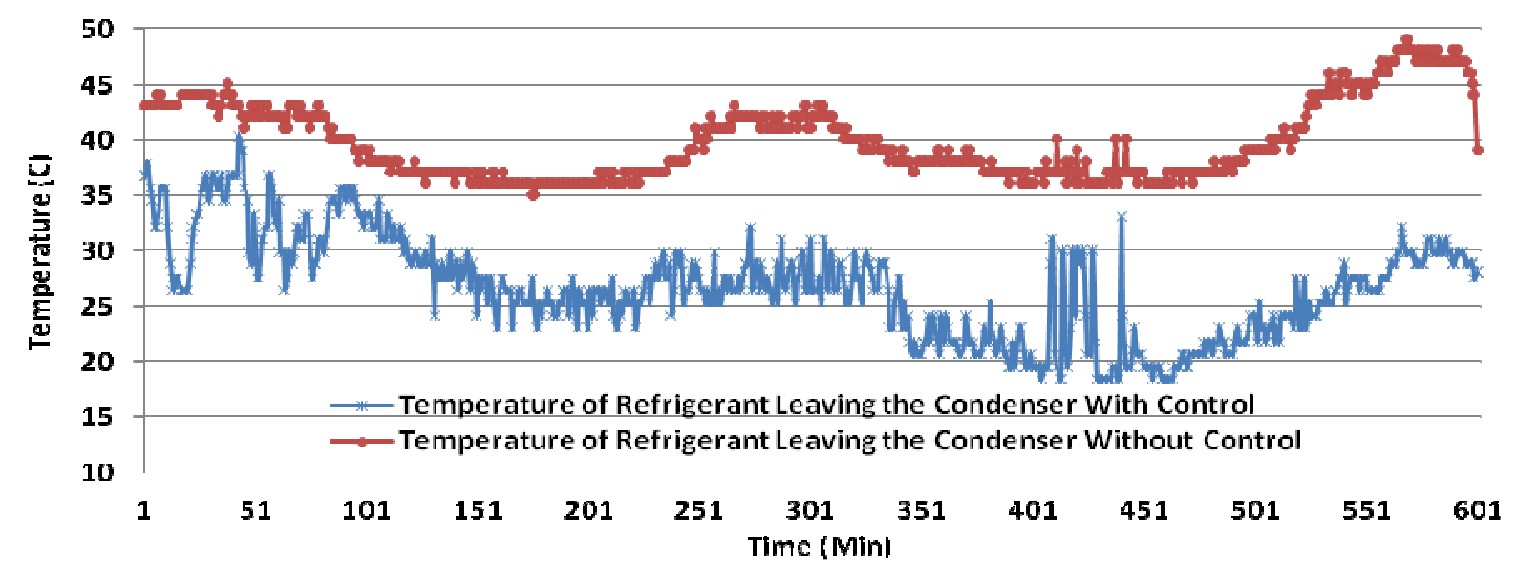

Figure 5-Temperatures of refrigerant entering and leaving the condenser

\section{CONCLUSION}

In this paper, we have investigated the performance of a fully-developed, solar-assisted, splitsystem air-conditioner of $6 \mathrm{~kW}$ cooling capacity. In this design, a by-pass line is implemented in the discharge line after the compressor to control the refrigerant mass flow rate via a two-way proportional valve. A dynamic mode is derived and the linear quadratic regulator technique is applied to control the valve in order to adjust the refrigerant mass flow rate to achieve optimal set-points of the refrigerant temperature profiles. The obtained results for the closed-loop system under control have shown that the new design outperforms a conventional system in terms of energy efficiency. This is due to the higher refrigeration effect in the direct expansion evaporator which allows for a performance gain. Thus, the new design is promising for improving the system performance while fulfilling the cooling demands as well as achieving high energy efficiency. 


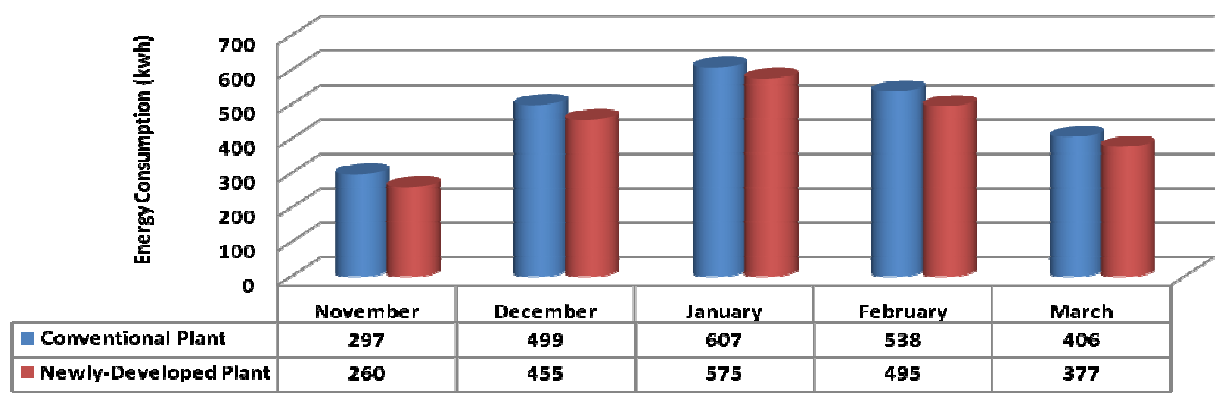

Figure 6- Energy consumption comparison

\section{REFERENCES}

Al-Abidi, A.A., Mat, S.F., Sopian, K., Sulaiman, M.Y., Lim, C.H., and Th, A. (2012). Review of thermal energy storage for air conditioning systems. Renewable and Sustainable Energy Reviews, 16, 5802-5819.

ANSI/ASHRAE Standard 140. (2007). Standard Method of Test for the Evaluation of Building Energy Analysis Computer Program. American Society of Heating, Refrigerating and Air-Conditioning, Atlanta, GA, USA.

Choudhury, B., Chatterjee, P.K., and Sarkar, J.P. (2010). Review paper on solar-powered air-conditioning through adsorption route. Renewable and sustainable energy reviews, 14, 2189-2195.

Fu, H.D., Pei, G., Ji, J., Long, H., Zhang, T., and Chow, T.T. (2012). Experimental study of a photovoltaic solar-assisted heat pump/heat pipe system. Applied Thermal Engineering, 40, 343-350.

Guo, J., and Shen, H.G. (2009). Modeling solar-driven ejector refrigeration system offering air conditioning for office buildings. Energy and Buildings, 41, 175-181.

Ha, Q. (2012). Data acquisition, monitoring and control for hybrid solar air-conditioners. Gerontechnology, vol. 11, 314.

Ha, Q.P., and Vakiloroaya, V. (2012). A novel solar-assisted air conditioner system for energy savings with performance enhancement. Procedia Engineering, 49, 116-123.

La, D., Dai, Y., Li, Y., Ge, T., and Wang, R. (2011). Case study and theoretical analysis of a solar driven two-stage rotary desiccant cooling system assisted by vapor compression air-conditioning. Solar Energy, 85, 2997-3009.

Liang, C.H., Zhang, X.S., Li, X.W., and Zhu, X. (2011). Study on the performance of a solar assisted air source heat pump system for building heating. Energy and buildings, 43, 2188-2196.

Sukamongkol, Y., Chungpaibulpatana, S., Limmeechokchai, B., and Sirpadungtham, P. (2010). Condenser heat recovery with a PV/T air heating collector to regenerate desiccant for reducing energy use of an air conditioning room. Energy and Buildings, 42, 315-325.

TRNSYS software. (2006). A transient system simulation program., version 16 $<$ http://sel.me.wisc.edu/trnsys/.> 
Vakiloroaya, V., Dibbs, R., Ha, Q.P., and Samali, B. (2012). Hybrid solar air-conditioner modeling and optimal usage for energy saving and comfort enhancement. Proc. the Second International Conference on Building Energy and Environment, (pp. 711-718). Colorado, USA.

Vakiloroaya, V., Ha, Q.P., and Samali, B. (2013). Energy-Efficient HVAC systems: simulation-empirical modeling and gradient optimization. Automation in Construction, 31, 176-185.

Vakiloroaya, V., Zhu, J.G., Ha, Q.P. (2011). Modelling and optimisation of direct expansion air conditioning systems for commercial building energy savings. Proc. Int. Symp. Automation and Robotics in Construction (pp. 232-237). Seoul, Korea.

Xu, S.M., Huang, X.D., Du, R. (2011). An investigation of the solar powered absorption refrigeration system with advanced energy storage technology. Solar Energy, 85, 1794-1804. 